\title{
STABILITY OF WHEELED ARMOURED PERSONNEL CARRIER FIRING SIDEWAYS
}

\author{
Andrzej Wiśniewski, Piotr Rybak \\ Military University of Technology \\ gen. Sylwestra Kaliskiego Street 2, 00-908, Warsaw, Poland \\ tel.: +48261837346 \\ e-mail:wisniewski.andrzej@wat.edu.pl,piotr.rybak@wat.edu.pl
}

\begin{abstract}
One of the most important and commonly used means of transport in the armed forces of various countries is wheeled armoured personnel carriers. After proper preparation, beside transport tasks, they can carry out special tasks, as part of regular and irregular activities within purpose of supporting actions of troops. This paper presents preliminary results of numerical research of wheeled armoured personnel carrier with 8x8-drive system. The effect of impact of large calibre cannon $(120 \mathrm{~mm})$ with reduced recoil force on transporter behaviour was investigated. The research object model consists of shell, solid and discrete elements. The research was carried out in the LS-DYNA software. Considered variant applies to sideways firing (to the left of the vehicle) for cannon elevation angle 16 deg. Numerical model of standing still on the flat ground wheeled armoured personnel carrier was preloaded with the gravitational force. The results of post-firing vehicle behaviour including angular displacement of the hull, dynamic deflections of the suspensions and impact on the stability of the wheeled vehicle were evaluated.
\end{abstract}

Keywords: wheeled vehicle, vehicle dynamics, vehicle stability, armament, finite element method

\section{Introduction}

Modern vehicles in most cases are constructed as universal platforms. Depending on the type of mission, they can fulfil various tasks on the battlefield. In case of offensive tasks, they can be equipped with cannons with calibre $30-120 \mathrm{~mm}, 120 \mathrm{~mm}$ calibre mortars and fire-forget guided missiles launcher platforms. In case of vehicles with a modular construction, such as Boxer (see Fig. 1), adaptation of vehicle role on the battlefield involves the replacement of specialized "container" module. There is however also a group of vehicles in which the concept of universality depends on the construction of the vehicle in basic version (it is necessary to modify roof plate structure). New variant may be affected with the increase of total weight, overall height (easier identification and tracking of the vehicle), and position of the centre of mass.

a)

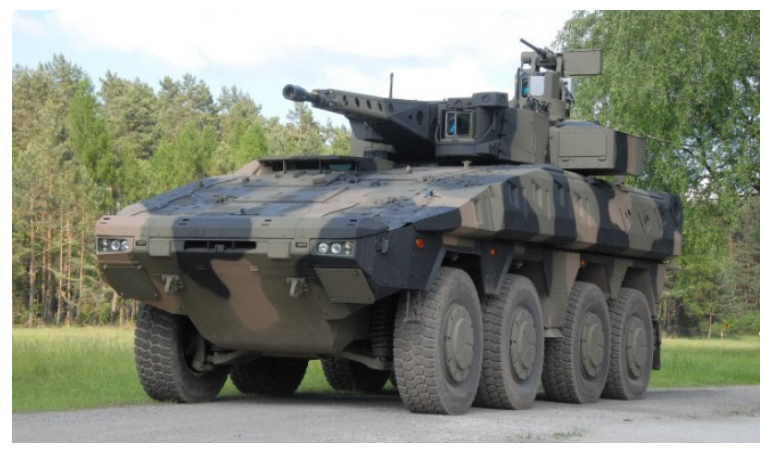

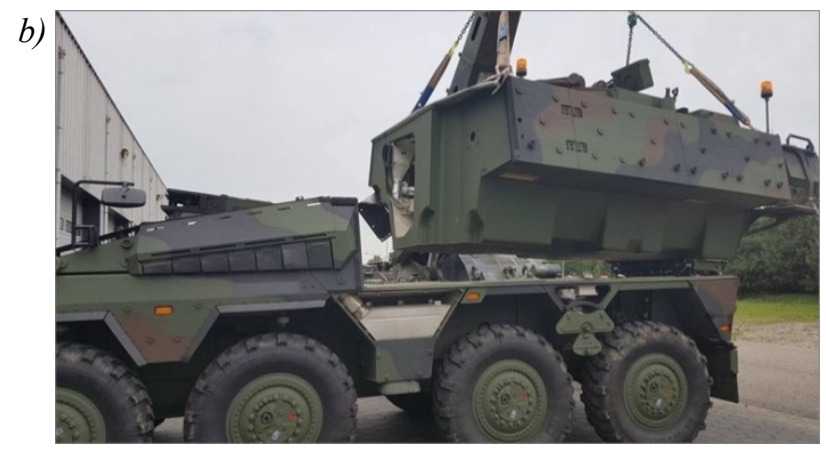

Fig. 1. Armoured Fighting Vehicle Boxer in variant: a) equipped with 30 mm cannon module [1], b) during specialized module replacement [2]

High position of the centre of the mass may negatively affect both safety of the crew of vehicle 
in two ways. Firstly, it affects the vehicle physical properties. Especially, when driving of paved roads such as increased risk of losing the stability of vehicle causing in the extreme case vehicle rollover. Additionally, it may occur damage to equipment and exposure of the crew to an immediate threat to life and health (bruises, fractures, etc.) excluding highly trained crew for the convalescence period. Secondly, in the case of vehicle equipped with larger calibre cannon characterized by recoil force about of hundreds of thousands of Newton. During firing, especially after firing sideways, depending on the slope of the terrain on which vehicle is located, in unfavourable conditions, stability of vehicle may be lost. This can lead to similar negative effects described above.

\section{Object of the research}

The object of research is a wheeled armoured transporter with $8 \times 8$ drive system configuration. The MES model of the vehicle (see Fig. 2) consists of shell, solid and discrete elements. The model of the Hitfist-30P tower has been modified to reflect the mass characteristics corresponding to a vehicle equipped with a tower with a $120 \mathrm{~mm}$ cannon.

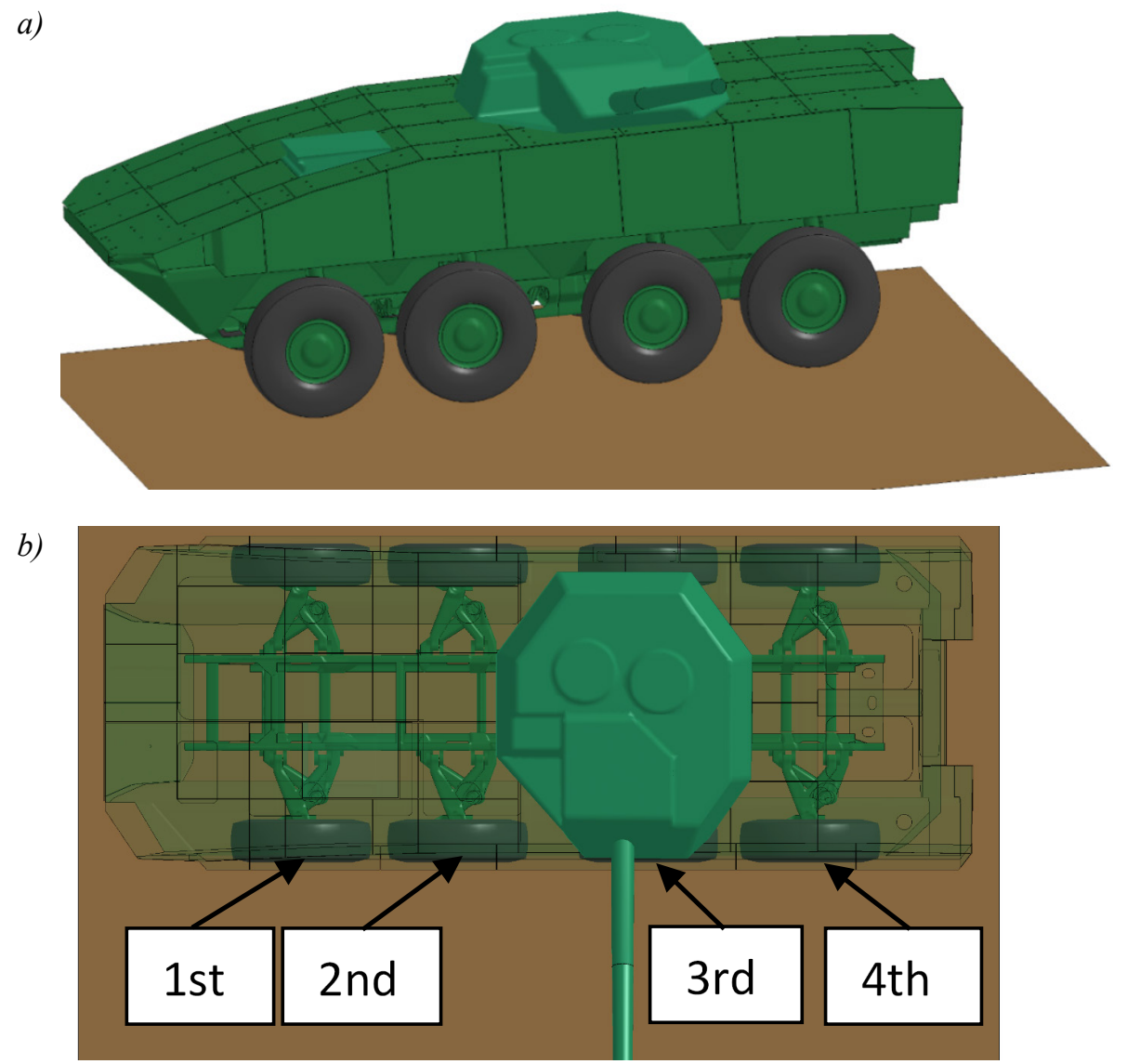

Fig. 2. Wheeled Armoured Personnel Carrier: a) 3d view of the research object, b) top view of vehicle with axles numbering

\section{Scope of research}

The scope of the research is to determine the impact of the recoil force on the vehicle hull behaviour. Firing sideways (to the left) task, for cannon elevation angle 16 deg. in model research was carried out for standing still vehicle on the flat ground. The hull behaviour (angular displacement) after firing, including suspension dynamic deflection and ground reaction forces will be analysed. 
The recoil force is time depended. Complex process taking place during firing is replaced with approximated approach. Its main assumption is that real force acting on vehicle is being replaced with rectangular impulse. Such impulse is described with constant magnitude and fixed duration time with comparable energy as real one. It is possible to apply Vallier's formula to determine average value of recoil resistance force [3]:

$$
\begin{gathered}
R=\frac{0.5 \cdot M_{0} \cdot v_{\text {max }}^{2}}{L_{\max }-L_{k}+v_{\text {max }} \cdot t_{p}}, \\
v_{\text {max }}=\frac{M_{p}+\beta \cdot m_{m}}{M_{0}} \cdot v_{0}, \\
\beta=\left(\frac{700+v_{0}}{v_{0}}\right)^{1.1},
\end{gathered}
$$

where:

$R \quad$ - recoil force resistance,

$v_{\max }-$ maximum velocity of the free recoil (at $R=0$ ),

$L_{\max }$ - maximum recoil path,

$L_{k} \quad$ - free recoil path (at $R=0$ ),

$t_{p}$ - duration of gunpowder gases exhaust activity,

$M_{p}$ - projectile mass,

$v_{0} \quad$ - initial velocity of the projectile

$m_{m}$ - mass of propellant charge,

$M_{0}$ - mass of recoiling assembly,

$\beta-$ activity of gunpowder gases factor.

Table 1 presents magnitude and time duration for cannons designed especially for tanks. Wheeled armoured personnel carrier compared to tank have higher position of the centre of mass and lower mass. Wheeled vehicles are equipped in different type of cannons. For direct firing support vehicles, lower calibre cannon may be used (with reduced firepower). Other option is to use high calibre cannon $(120 \mathrm{~mm})$ with reduced recoil force acting on vehicle in longer time. Assumed for numerical investigation canon is characterized by low recoil force with magnitude $300 \mathrm{kN}$ and duration $80 \mathrm{~ms}$.

Tab. 1. Recoil force comparison [4, 5]

\begin{tabular}{|c|c|c|}
\hline Ammunition & $\begin{array}{c}\text { Recoil force } \\
{[\mathrm{kN}]}\end{array}$ & $\begin{array}{c}\text { Duration } \\
{[\mathrm{ms}]}\end{array}$ \\
\hline $120 \mathrm{~mm}$, L44 cannon & 411 & 58 \\
\hline $120 \mathrm{~mm}$, L55 cannon & 597 & 49 \\
\hline
\end{tabular}

\section{Numerical research results}

As result of numerical research, a series of information was obtained allowing initial assessment of the impact of the use of a $120 \mathrm{~mm}$ cannon, characterized by reduced recoil force on the stability of a wheeled vehicle. Fig. 3a presents the view of the preloaded vehicle at time $t=0 \mathrm{~s}$ (before firing). Figs. 3b-3d presents the behaviour of the vehicle post-firing. The behaviour of independent suspensions on both sides of the vehicle may be observed. In Fig. 3b, the hull rotation may be observed. As result, the left side of the hull rises. Fig. $3 \mathrm{c}$ presents the vehicle at the maximum hull rotation, while Fig. $3 \mathrm{~d}$ presents load of the suspension on the left side of the vehicle (return phase, suspension is working off the impulse of the recoil force generated by the firing). 
a) $t=0 \mathrm{~s}$

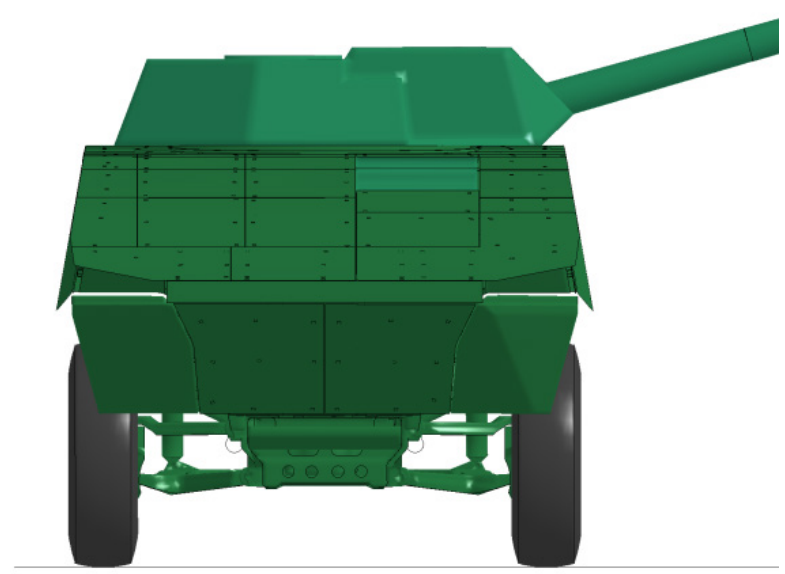

c) $t=0.384 \mathrm{~s}$

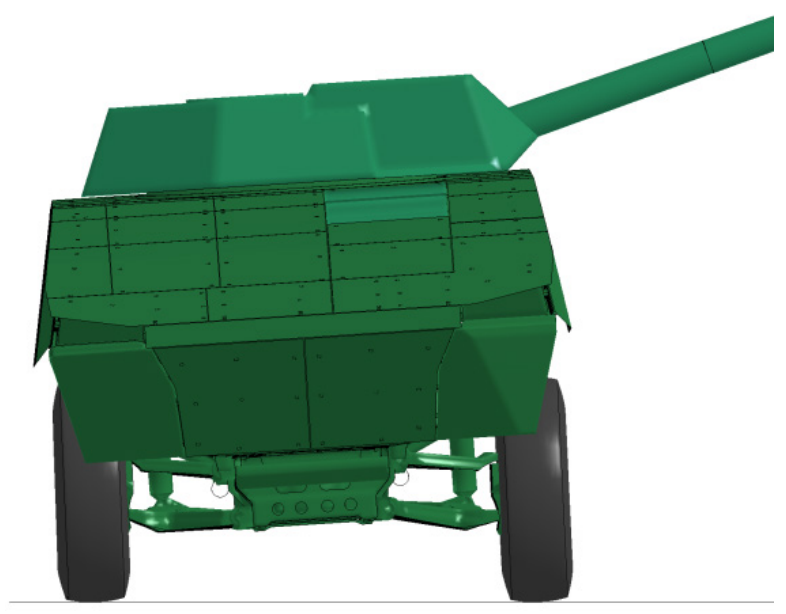

b) $t=0.192 \mathrm{~s}$

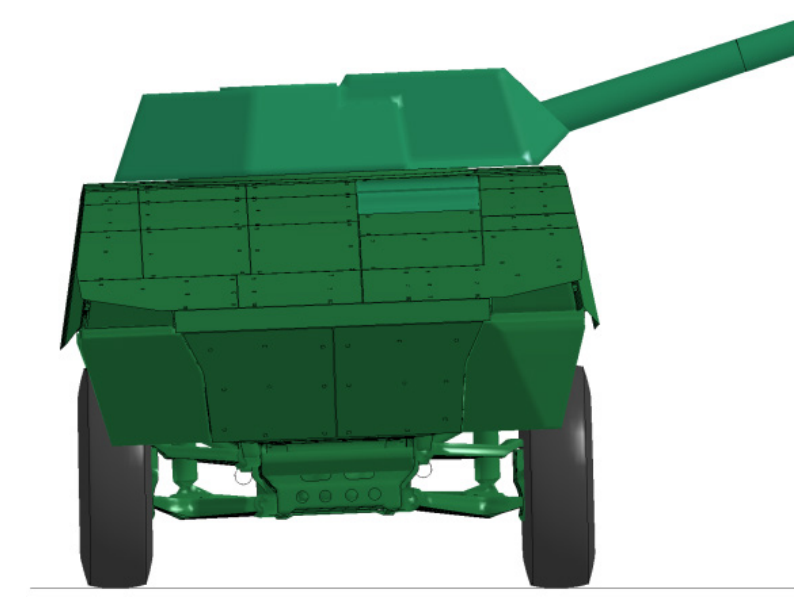

d) $t=0.42 \mathrm{~s}$

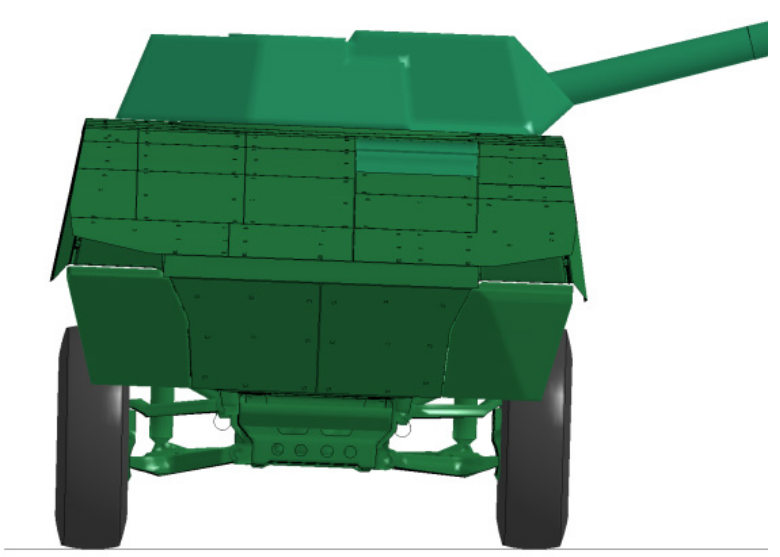

Fig. 3. Behaviour of the vehicle firing left, cannon elevation angle $16^{\circ}:$ a) vehicle before firing $(t=0)$, $b$-d) vehicle after firing for timestamps given above drawings

Figures 4a-d presents the dynamic deflection of the suspensions (black line for the left side and continuous blue for the right side of the vehicle): for the first, second, third and fourth axle. After firing to the left in the initial phase, the expansion of the hydraulic elastic-damping elements of the suspension on the left side of the vehicle is observed, as well as compression of those on the right side. Due to the location of the tower (and therefore the point of application of the recoil force) near the third axle of the vehicle, the largest dynamic deflections of the suspensions are observed for the third and fourth axle.

Figure 5 presents the lateral rotation of the hull after firing. Hull rotation from the static position did not exceed 4 deg., which should not be a drawback to the cannon position stabilizing systems.

In order to determine the stability of the vehicle, the dynamic reactions of the ground for subsequent wheels on the left side of the vehicle were reviewed. The criterion for maintaining stability is no detachment of wheels from ground, both during and after firing.

Figures 6a-d presents dynamic reactions of the ground for subsequent wheels of the left side of the vehicle for subsequent axles. Minimum values of force at the level of $20 \mathrm{kN}$ allow to state that for the considered scenario there was a reserve of stability - there was no risk of rollover of the vehicle. 
a)

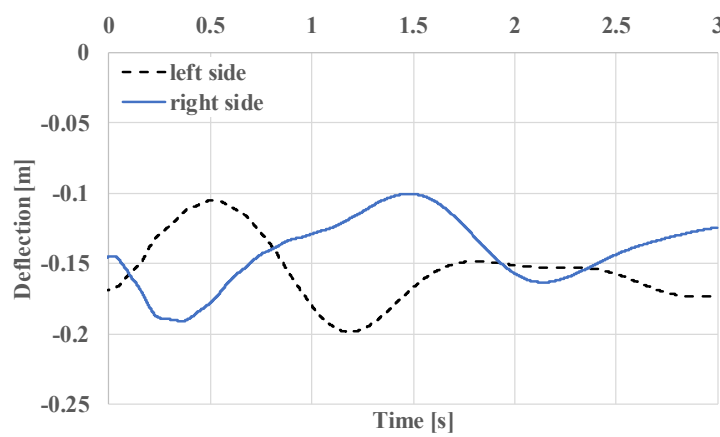

c)

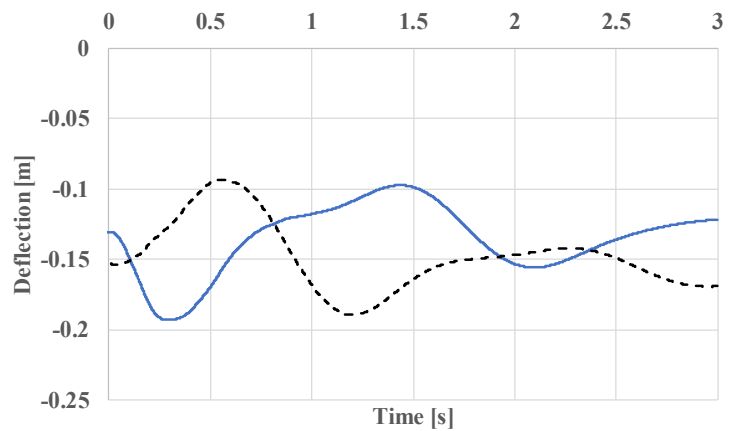

b)
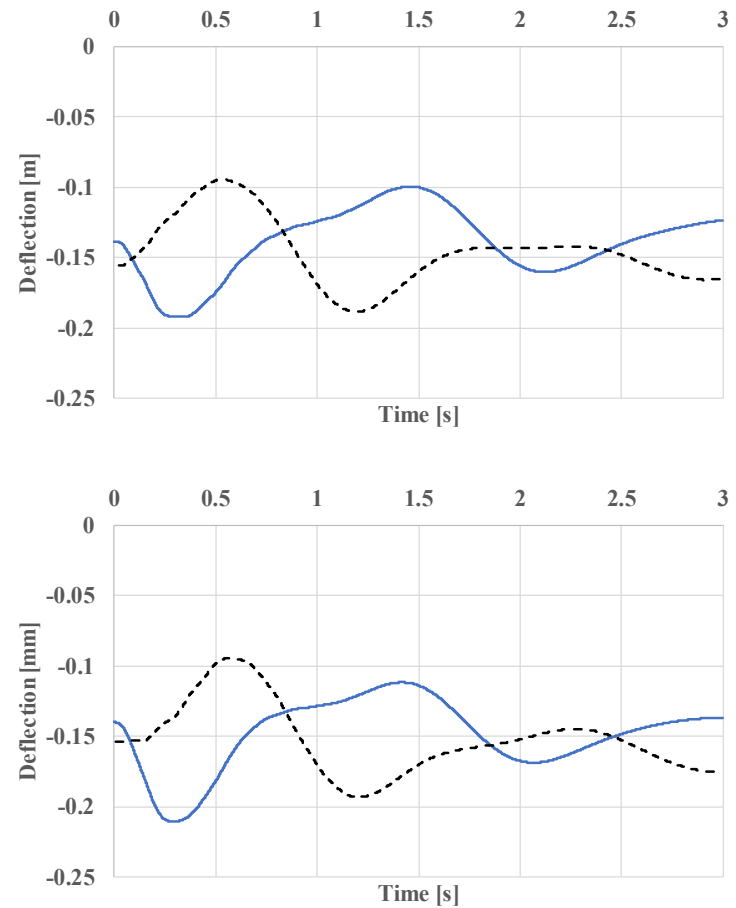

Fig. 4. Suspension dynamic deflection for both sides: a) first axle, b) second axle, c) third axle, d) fourth axle

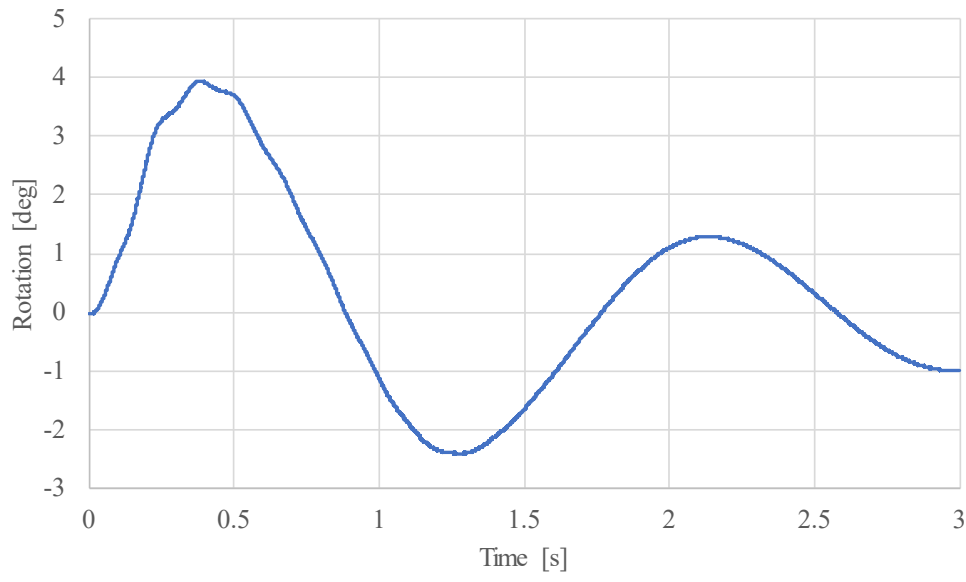

Fig. 5. Hull rotation

\section{Conclusion}

The paper presents preliminary results of numerical research of a wheeled armoured personnel carrier loaded with the recoil force after firing from cannon with a calibre of $120 \mathrm{~mm}$ with reduced recoil force. The test was carried out for firing sideways (to the left) for cannon elevation angle 16 deg., for standing still, preloaded with gravitational force vehicle on the flat ground.

Hull rotational displacement, dynamic deflection of suspensions and reactions of the ground allow concluding, that considered wheeled armoured transported used in previously described conditions did not affect negatively the vehicle stability. The proposed work considers favourable conditions use of armament. In real scenarios, it may be necessary to use armament in such cases as terrain with different inclination angle and the conducting firing tasks while driving. It is advisable to extend the research with such scenarios and to define the time necessary to achieve continuous firing. The developed wheeled vehicle model allows determining restrictions for firing while maintaining full stability, as well as optimization of construction parameters responsible for its maintenance on different road surfaces. 
a)

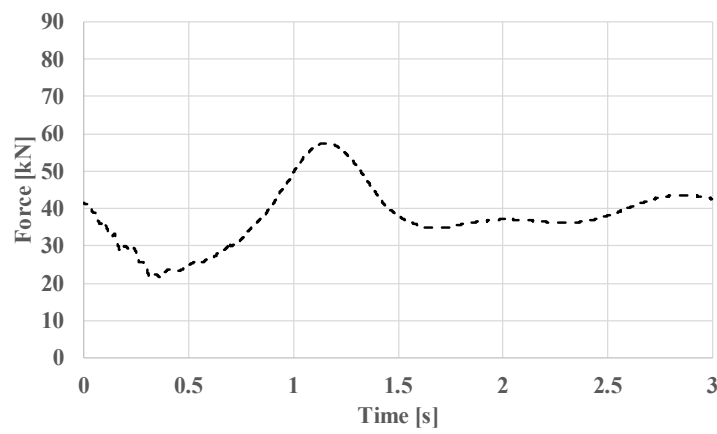

c)

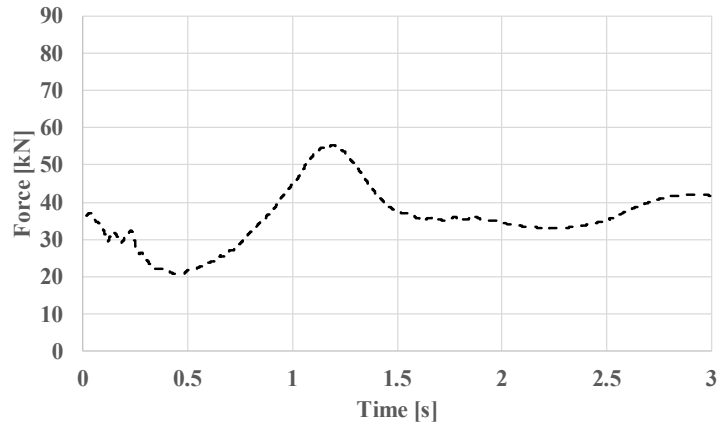

b)

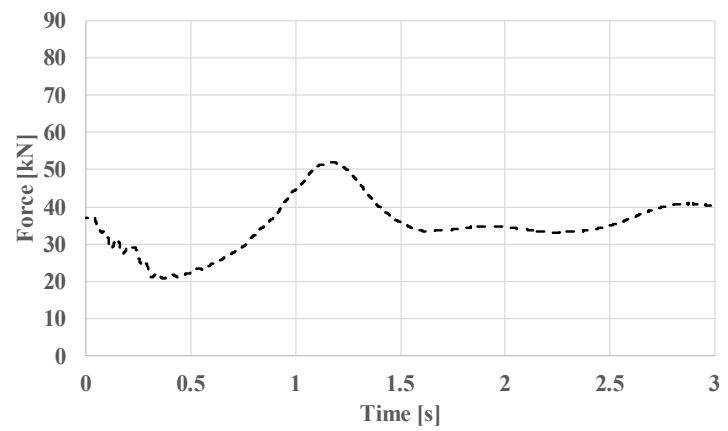

d)

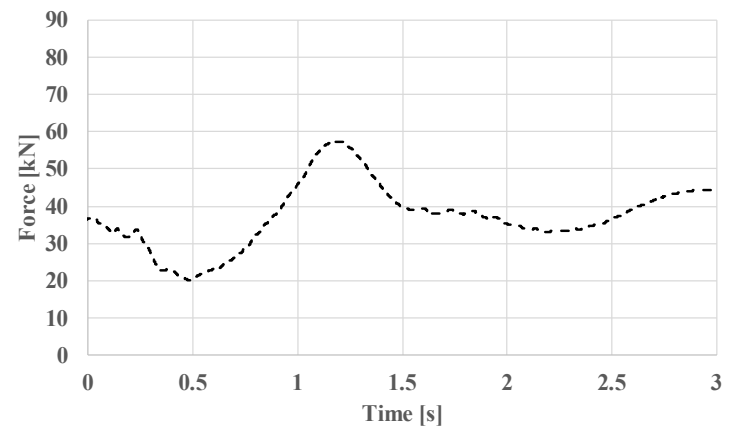

Fig. 6. Ground reaction force for wheels on the left side: a) first, b) second, c) third, d) fourth

\section{References}

[1] By Graham Robson-Parker - Own work, CC BY-SA 4.0, https://commons.wikimedia.org/w/ index.php?curid=50055652.

[2] https://u0v052dm9wl3gxo0y3lx0u44wz-wpengine.netdna-ssl.com/wp-content/uploads/2018/03/ Boxer-Module-Change-2-750x430.jpg.

[3] Borkowski, W., Figurski, J., Walentynowicz, J., Hryciów, Z., The Impact of the Cannon on the Combat Vehicle Chasis During Firing. Journal of KONES, Vol. 14, No. 1, Warsaw 2007.

[4] Borkowski, W., Rybak, P., Hryciów, Z., Wysocki, J., Michałowski, B., Combat Vehicle Dynamic Load Tests in the Aspect of the Operation Safety. Journal of KONBIN, Vol. 13, No. 1, 2010.

[5] Figurski, J., Rybak, P., Fighting Means Quality and Military Vehicle Load, Journal of KONES, Vol. 14, No. 2, Warsaw 2007. 